\title{
Mesenchymal stem cells combined with liraglutide relieve acute lung injury through apoptotic signaling restrained by PKA/ $\beta$ - catenin
}

Xiaotong Yang ${ }^{1,2}$, Xiaoying Ma ${ }^{2}$, Ocholi Don ${ }^{1}$, Yuanlin Song ${ }^{3}$, Xiaoyan Chen ${ }^{4}$, Jianwen Liư ${ }^{2^{*}}$, Jieming Qu ${ }^{1,5^{*}}$ and Yun Feng ${ }^{1,5^{*}}$ (D)

\begin{abstract}
Background: ARDS and ALI are life-threatening diseases with extremely high mortality in patients. Different sources of MSCs could mitigate the symptoms of ALI from diverse mechanisms. Liraglutide is an activator of glucagon-like peptide-1 receptor (GLP-1R) that activates anti-apoptotic pathways and exerts anti-inflammatory effects. We mainly compared the effects of human chorionic villus-derived mesenchymal stem cells (hCMSCs), human bone marrowderived mesenchymal stem cells (hBMSCs), and human adipose-derived mesenchymal stem cells (hAMSCs) on the treatment of ALI and explored the apoptosis mechanism of combination MSCs of liraglutide.
\end{abstract}

Methods: The proliferation of MSCs was detected by MTT assay. Western blot and RT-qPCR were used to detect the expression of GLP-1R, SPC, Ang-1, and KGF in MSCs stimulated by LPS and liraglutide. By using flow cytometry and TUNEL assay to compare the apoptosis of three MSCs under the action of LPS and liraglutide, we selected hCMSCs as the target cells to study the expression of apoptotic protein through the PKA/ $\beta$-catenin pathway. In ALI animal models, we observed the effects of liraglutide alone, MSCs alone, and MSCs combined with liraglutide by H\&E staining, cell counting, immunohistochemistry, and ELISA assay.

Results: We demonstrated that LPS attenuates the proliferation of the three MSCS and the expression of GLP-1R. Liraglutide could reverse the effects of LPS; increase the expression of SPC, Ang-1, and KGF; and can reduce the apoptosis of three MSCs through the PKA/ $\beta$-catenin pathway. In the LPS-induced ALI model, MSCs combined with liraglutide showed a significant therapeutic effect, and hCMSCs combined with liraglutide have advantages in the treatment of ALI.

Conclusions: The therapeutic effect of combination MSCs of liraglutide on ALI was higher than that of MSCs alone or liraglutide alone, and liraglutide could alleviate the symptoms of ALI by reducing MSCs apoptosis.

Keywords: ARDS, ALI, Liraglutide, Mesenchymal stem cells, Cell apoptosis

\footnotetext{
*Correspondence: liujian@ecust.edu.cn; jmqu0906@163.com;

Fy01057@163.com

${ }^{2}$ State Key Laboratory of Bioreactor Engineering \& Shanghai Key Laboratory of New Drug Design, School of Pharmacy, East China University of Science and Technology, Shanghai 200237, China

'Department of Respiratory and Critical Care Medicine, Ruijin Hospital, School of Medicine, Shanghai Jiao Tong University, Shanghai 20025, China

Full list of author information is available at the end of the article
} 


\section{Background}

In critically ill patients, acute lung injury (ALI) and acute respiratory distress syndrome (ARDS) are the leading causes of acute respiratory failure and have a high mortality ratio [1]. The characteristics of ARDS and ALI are mainly the complex relationship between the immune system and alveolar capillaries, leading to acute pro-inflammatory reactions [2], accompanied by increased pulmonary protein permeability, enhanced pulmonary edema, slowed alveolar clearance, and ultimately impaired gas exchange and hypoxemia [3-5]. The current main therapeutic strategies are supportive treatments [6], including lung-protective ventilation [7], prone positioning [8], early neuromuscular blockade [9], and conservative fluid management [10]. However, the therapeutic effect was not significantly improved [7], and effective treatment strategies are urgently required. Lipopolysaccharide (LPS) has been identified as a cause of ALI [11], which could directly damage endothelial cells and indirectly activates neutrophils and macrophages to exert toxic effects on pulmonary [12].

Recently, using of mesenchymal stem cells (MSCs) in the treatment of ALI has proven to be effective [13]. They secrete paracrine factors that regulate lung endothelial and epithelial permeability, including growth factors, antimicrobial peptides, and anti-inflammatory cytokines, which could alleviate damaged alveolar fluid clearance, improve lung permeability, and mitigate inflammatory disorders [14-18]. In addition, MSCs are widely available and can be collected from the bone marrow [19], adipose tissues [20], placenta [21], umbilical cord [22], and other tissues [23, 24]. However, inflammatory stimulation in the ALI lung microenvironment could lead to a decrease in MSC survival and weaken paracrine capacity [24]. Several studies have been reported to identify strategies to ameliorate and improve the efficiency of MSC therapy [13, 14, 25].

Glucagon-like peptide-1(GLP-1) is an endogenous 30amino acid peptide synthesized by enteroendocrine L cells and secreted throughout the small intestine and ascending colon which influence the absorption of nutrients [26]. Liraglutide is a long-acting glucagon-like peptide analog that targets the GLP-1 receptor (GLP-1R) [27]. Studies have shown that liraglutide has a good anti-inflammatory function and could regulate the inflammatory response to limit the progression of atherosclerosis in vivo [28]. In addition, it was reported that liraglutide could treat myocardial infarction by increasing myocardial blood flow, inhibiting cardiomyocyte apoptosis, and enhancing cardiac function [29]. It has also been found in our previous research that liraglutide can be combined with MSCs to alleviate the symptoms of ALI [30].

Based on above investigation, we aimed to contrast the comparison of human chorionic villus-derived mesenchymal stem cells (hCMSCs), human bone marrow-derived mesenchymal stem cells (hBMSCs), and human adipose- derived mesenchymal stem cells (hAMSCs) under the action of LPS and liraglutide. The protective effects of three MSCs combined with liraglutide on ALI animal models were examined simultaneously. Furthermore, we assessed the anti-apoptotic effect of liraglutide on MSCs by activating the PKA/ $\beta$-catenin pathway to suppress the Bax, Bcl-2, cleaved caspase- 9 , and cleaved caspase- 3 apoptotic signaling pathways.

\section{Methods}

\section{Cell culture and transfection}

hCMSCs and hBMSCs were characterized by staining with antibodies against CD44, CD73, CD90, CD105, CD34, and CD45 and then detected by flow cytometry as described in our previous study [31]. hAMSCs were kindly provided by Dr. Chuandong Wang (Department of Orthopedic Surgery, Xin Hua Hospital Affiliated to Shanghai JiaoTong University School of Medicine, Shanghai, China) and were verified by staining with antibodies against CD34, CD45, CD73, CD90, and CD105 and then detected by flow cytometry as described in Wang's article [32]. MSCs were cultured in mesenchymal stem cell medium (ScienCell, Cat. No. 7501, USA) in a humidified atmosphere at $37^{\circ} \mathrm{C}$ and $5 \% \mathrm{CO}_{2}$. MSCs were harvested at approximately $80-90 \%$, and the culture medium was changed every $2-3$ days.

Cells were seeded onto desired size plates to reach $70-90 \%$ and then transfection was performed using Lipofectamine $^{\mathrm{mm}} 2000$ (Thermo Fisher Scientific, 11668027, USA) according to the manufacturer's protocol. The siGLP-1R were synthesized by Hanbio Biotechnology Co., Ltd. (Shanghai, China). The sequences are as follows:

Hs-GLP-1R-si-1

5'-GGAAGACUGUCAACACUAAdTdT-3'; 5'-UAGAAA UCUAUCUUUGUCCdTdT-3';

Hs-GLP-1R-si-2

5'-GAAUAGUCUGUGUGCACAAdTdT-3';5'-UUGUGC ACACAGACUAUUCdTdT-3';

Hs-GLP-1R-si-3

5'-GGAAGGAUGUGCUUUCCUAdTdT-3'; 5' -UAGGAAAGCACAUCCUUCCdTdT-3';

Negative control (NC)

5'-UUCUCCGAACGUGUCACGdTdT-3'; 5'-ACGUGA CACGUUCGGAGAAdTdT-3'.

The Si-GLP-1R silencing efficiency was determined 48 $\mathrm{h}$ post transfection by protein and mRNA analysis for future experiments.

\section{MTT assay}

MTT (3-(4,5-dimethylthiazol-2-yl)-2,5-diphenyltetrazolium bromide) assay was used to detect cell viability of three different MSCs. The three MSCs were at $1 \times 10^{4}$ cells/well in 96-well plates and then divided into three groups: (i) no treatment (control group), (ii) treated with $30 \mu \mathrm{g} / \mathrm{mL}$ LPS 
(L2880, Sigma, USA) (LPS group), and (iii) treated with $30 \mu \mathrm{g} / \mathrm{mL}$ LPS and $10 \mathrm{nM}$ liraglutide (MK, Cat. No. 204656-20-2, China) (LPS + liraglutide group). The concentrations of LPS and liraglutide were selected based on previous studies of MSCs viability [30]. After 6, 24, 48, and $72 \mathrm{~h}$ of incubation, $10 \mu \mathrm{L}$ of $5 \mathrm{mg} / \mathrm{mL}$ MTT (M2128, Sigma, USA) solution was added to each well and continued to culture at $37^{\circ} \mathrm{C}$ for $4 \mathrm{~h}$. Cells were lysed using $100 \mu \mathrm{L}$ of dimethylsulfoxide (DMSO, 67-68-5, Sigma, USA). The optical density (OD) was measured at both $492 \mathrm{~nm}$ and 630 $\mathrm{nm}$ wavelength. Date represents the mean of four wells at each point.

\section{Western blot assay}

To verify the expression of KGF, SPC, GLP-1, and GLP$1 \mathrm{R}$, MSCs were exposed to $30 \mu \mathrm{g} / \mathrm{mL}$ LPS or $10 \mathrm{nM}$ liraglutide. To verify the PKA/ $\beta$-catenin pathway, MSCs were exposed to $10 \mathrm{nM}$ liraglutide or $100 \mathrm{nM}$ SiRNA or $20 \mu \mathrm{M}$ PKA inhibitor H89 (MCE, Cat. No. 130964-39-5, USA) on the premise of exposure to $30 \mu \mathrm{g} / \mathrm{mL}$ LPS. Proteins were extracted from differently treated MSCs. The protein concentration was determined using the BCA assay (CST, \#7780, USA). Proteins were separated on SDS-PAGE gel ahead of being transferred on PVDF membranes (Life Technologies, USA). The PVDF membrane was blocked in $5 \%$ BSA solution for $3 \mathrm{~h}$, after which the different primary antibodies were applied overnight including Angiopoietin 1 (Ang-1, Abcam, ab102015,UK), GLP-1R (Novus, NBP1-97308, USA), SFTPC (SPC, Abclonal, A1835, USA), KGF (Abcam, ab131162 UK), p- $\beta$-catenin (Santa Cruz, sc57535, USA), $\beta$-catenin (Wanleibio, WL0962a, China), cleaved caspase-3 (Abcam, ab49822,UK), cleaved caspase9 (Abways, CY5682, Chian), Bax (Wanleibio, WL03446, China), and Bcl-2 (Abways, CY6717, China). GAPDH (Santa Cruz, sc-166574, USA) was used as a loading control of total protein. The membranes were then incubated with HRP secondary antibody (Jackson ImmunoResearch Laboratories, 111-035-003, 115-035-003, China). The blots were detected by ECL technique.

\section{RT-qPCR assay}

Total RNA was extracted from three different MSCs using TRIzol reagent (Invitrogen, 15596-026, USA). TransScript First-Strand cDNA Synthesis SuperMix (Transgene Biotech, AH341-01, China) was used for cDNA synthesis following the manufacturer's instruction. The RT-qPCR was carried out on an CFX96 (BioRad, USA) and TransStart Top Green qPCR SuperMix (Transgene Biotech, AQ131-01, China) with a genespecific primer (Table 1). The relative expression of gene was expressed as a function of threshold cycle $(\mathrm{Ct})$ and analyzed by $2^{-\Delta \Delta C t}$ method.
Table 1 The sequence of primers

\begin{tabular}{ll}
\hline Gene & Primers \\
\hline GLP-1R & F:5'- ATCACAGTGGCGAGAGGAGAG-3' \\
SPC & R:'-CCAAGTGATGCAAGCAGAGG-3' \\
& F: 5'-GGGTCATCCAGGCAACTCGG-3' \\
KGF & R: 5'-CTTTCCCGTGGGGCTCC-3' \\
& F: 5'-GACAGCAGACACGGAACTCT-3' \\
Rng-1 5'-AGTCGTCGCTCTTCCAAACT-3' & F: 5'-TGGCTTGGATGTGCAACCTT-3' \\
& R: 5'-CCCCCTCAAAGAAGCGTTG-3' \\
GAPDH & F:5'-TGCCAAATATGATGACATCAAGAA-3' \\
& R:5'- GGAGTGGGTGTCGCTGTTG-3' \\
\hline
\end{tabular}

\section{Immunofluorescence staining}

The $1 \times 10^{5}$ MSCs were plated in a 24-well plate, after treatment with LPS and liraglutide, hCMSCs, hBMSCs, and hAMSCs were fixed in $4 \%$ paraformaldehyde (solarbio, P1110, China) at $4{ }^{\circ} \mathrm{C}$ for $20 \mathrm{~min}$, washed with $0.1 \%$ BSA in PBS, and then permeabilized with $0.3 \%$ Triton $\times$ 100 (Sigma, 9002-93-1, USA) at room temperature. The cells were incubated with anti-GLP-1R antibody at $5 \mu \mathrm{g} /$ $\mathrm{mL}$ overnight at $4{ }^{\circ} \mathrm{C}$ and detected with anti-rabbit $\mathrm{Cy} 3$ (Jackson ImmunoResearch, 111-165-003, China) (red) 1: 100 dilution. Nuclei were stained with DAPI (Sigma, 28718-90-3, USA) (blue). MSCs were examined under a fluorescence microscope (Nikon, Japan). MSCs were imaged using a $\times 10$ objective. Randomly, they selected 8 fields of view for quantitative fluorescence analysis.

\section{Immunohistochemistry analysis}

The pulmonary tissue sections were incubated at $60{ }^{\circ} \mathrm{C}$ for $4 \mathrm{~h}$ and immersed in xylene twice for $20 \mathrm{~min}$ each, rehydrated by means of a graded series of ethanol, and then incubated with fresh $0.3 \%$ hydrogen peroxide in $100 \%$ methanol for $30 \mathrm{~min}$ at room temperature. The sections were then washed three times using PBS for 15 min. Antigen retrieval was performed with the ImmunoSaver antigen retriever system (Boster, AR0023, USA) at 98-100 ${ }^{\circ} \mathrm{C}$ for $30 \mathrm{~min}$, and sections were cooled to room temperature. Sections were then washed by PBS. Nonspecific binging sites were blocked by incubation with BSA solution (Boster, SA1022, USA) for $30 \mathrm{~min}$. The sections were then incubated with SFTPC antibody (Abclonal, A1835, USA) or Nanog antibody (Thermo Fisher Science, PA1-097, China) in a 1:100 dilution overnight at $4{ }^{\circ} \mathrm{C}$ and incubated with secondary antibodies at room temperature for $30 \mathrm{~min}$. The sections were performed according to the steps of the SABC immunohistochemical staining kit (Boster, SA1022, USA). The sections were imaged using a $\times 40$ objective.

\section{TUNEL analysis}

The TUNEL experiment (Beyotime, C1088, China) follows the instructions. The $1 \times 10^{5} \mathrm{MSCs}$ were plated in a 
24-well plate, divided into control groups, $30 \mu \mathrm{g} / \mathrm{ml} \mathrm{LPS}$ groups and $30 \mu \mathrm{g} / \mathrm{mL}$ LPS combined with $10 \mathrm{nM}$ liraglutide groups, and cultured for $72 \mathrm{~h}$. The MSCs were washed once with PBS, then fixed in $4 \%$ paraformaldehyde (solarbio, P1110, China) for $30 \mathrm{~min}$ at $4{ }^{\circ} \mathrm{C}$, and later incubated with 0.3\% Tritonx-100 (Sigma, 9002-931, USA) for $5 \mathrm{~min}$ at room temperature. After washing twice using PBS, the TUNEL solution (Beyotime, C1088, China) was added to each well and incubated at $37^{\circ} \mathrm{C}$ for $60 \mathrm{~min}$ in the dark. Afterwards, it was washed 3 times with PBS. DAPI (Sigma, 28718-90-3, USA) was incubated the nuclei in the dark at room temperature for $10 \mathrm{~min}$. MSCs were imaged using a $\times 20$ objective.

\section{Flow cytometric analysis}

MSC apoptosis were performed by an Annexin V-FITC/ propidiumiodide (PI) kit (4A Biotech, FXP018, China). MSCs were collected using different treatments and prepared $50 \mu \mathrm{L}$ of a $2 \times 10^{5}$ cell suspension in PBS. The MSCs were then incubated with Annexin V-FITC and PI for 5 min at room temperature and analyzed using a FACS Vantage cytometer (Becton Dickinson, USA). The proportion of apoptotic cells was analyzed by FlowJo software.

\section{In vivo modeling}

Four-week-old male SPF BALB/C mice were purchased from Cavensbiogle (Suzhou, China). The mice were kept in a conducive environment and, within a week, had adapted to it and able to freely access food and water. Mice were originally divided into nine groups (twelve mice per group): (i) PBS + PBS group, (ii) LPS + PBS group, (iii) LPS + liraglutide group, (iv) LPS + hCMSCs group, (v) LPS + hBMSCs group, (vi) LPS + hAMSCs group, (vii) LPS + hCMSCs+Liraglutide group, (viii) LPS + hBMSCs + liraglutide group, and (ix) LPS + hAMSCs + liraglutide group. After LPS stimulation, six mice were randomly selected from each group and classified into the $2 \mathrm{~d}$ model group and $7 \mathrm{~d}$ model group. In the LPS + PBS group, mice were slowly instilled via the trachea with $2.5 \mathrm{mg} / \mathrm{kg}$ LPS (dissolved in $50 \mu \mathrm{L}$ of $0.9 \%$ normal saline). The PBS + PBS group were injected with the same volume of $0.9 \%$ normal saline. The LPS + liraglutide group was injected with the same volume of LPS, and $20 \mathrm{~min}$ later, it was intraperitoneally injected $2 \mathrm{mg} /$ $\mathrm{kg}$ liraglutide every $12 \mathrm{~h}$. The LPS + hCMSCs group, LPS + hBMSCs group, and LPS + hAMSCs group were injected with the same volume of LPS which then $4 \mathrm{~h}$ later, $200 \mu \mathrm{L}$ PBS containing $5 \times 10^{5}$ different MSCs were injected into the tail vein. The LPS + hCMSCs + liraglutide group, LPS + hBMSCs + liraglutide group, and LPS + hAMSCs + liraglutide group were treated the same way as the LPS + hCMSCs group, LPS + hBMSCs group, and LPS + hAMSCs group. After $20 \mathrm{~min}$ of treatment, $2 \mathrm{mg} /$ $\mathrm{kg}$ of liraglutide was intraperitoneally injected every $12 \mathrm{~h}$
(4 times in $2 \mathrm{~d}$ model group and 14 times in $7 \mathrm{~d}$ model group) [33]. All animals were humanely killed by lethal overdose of sodium pentobarbital in $2 \mathrm{~d}$ and $7 \mathrm{~d}$ model group after LPS stimulation. The animal experiment flow chart is shown in Fig. 1.

\section{H\&E staining}

After $2 \mathrm{~d}$ or $7 \mathrm{~d}$ of LPS stimulation, mice were sacrificed and their pulmonary tissues were fixed in $4 \%$ paraformaldehyde overnight, embedded in paraffin, sectioned into $3-5 \mu \mathrm{m}$ thickness, and stained with hematoxylin and eosin (H\&E, Cat. No.C0105, Beyotime). The pathological changes of pulmonary tissues were observed under a microscope using $x$ 20 objective. According to the pulmonary tissue pathological damage score [34], the researchers were blinded to the group and randomly selected 10 fields of view in the $x$ 400 field of view, with each variable being scored with 0 to 4 points. The scoring criteria were as follows: no injury scored 0 , injury in $25 \%$ of the field scored 1, injury in $50 \%$ of the field scored 2, injury in $75 \%$ of the field scored 3, and injury throughout the field 4.

\section{Total protein concentration and inflammatory cell counts in the BALF}

After $2 \mathrm{~d}$ or $7 \mathrm{~d}$ of LPS stimulation, we collected the bronchoalveolar lavage fluid (BALF), and the supernatant was centrifuged to determine the total protein concentration by the BCA protein kit (CST, \#7780, USA). The total number of nucleated cells in the BALF was counted using a hemocytometer. The pellet was then resuspended in $200 \mu \mathrm{L}$ PBS. Ten microliters of cell suspension was added to the coverslip and stained with Wright-Giemsa staining solution (Solarbio, G1020, China); 200 cells were counted under 8 randomly selected fields using a microscope of $\times 100$ magnification.

\section{Wet-to-dry ratio (W/D)}

After $2 \mathrm{~d}$ or $7 \mathrm{~d}$ of LPS stimulation, mice were sacrificed and their lungs were collected. The severity of pulmonary edema was assessed by the wet-to-dry ratio (W/D). The left lower lung was weighted and then dehydrated at $60^{\circ} \mathrm{C}$ for $72 \mathrm{~h}$ in an oven.

\section{ELISA assay}

In vitro, three kinds of MSCs were seeded with $30 \mu \mathrm{g} / \mathrm{mL}$ LPS alone or with $10 \mathrm{nM}$ liraglutide after $72 \mathrm{~h}$. The culture media were collected and detected for the secretion of IL10 (Neobioscience, Cat. No. EMC005, China) and TGS-6 (RayBio, Cat. No. P98066, China). The BALF collected and detected the levels of Ang-1 (Dakewe, Cat. No. 100170-APH, China) and KGF (Dakewe, Cat. No. KOA0490, China) following the instruction of the ELISA kits. 


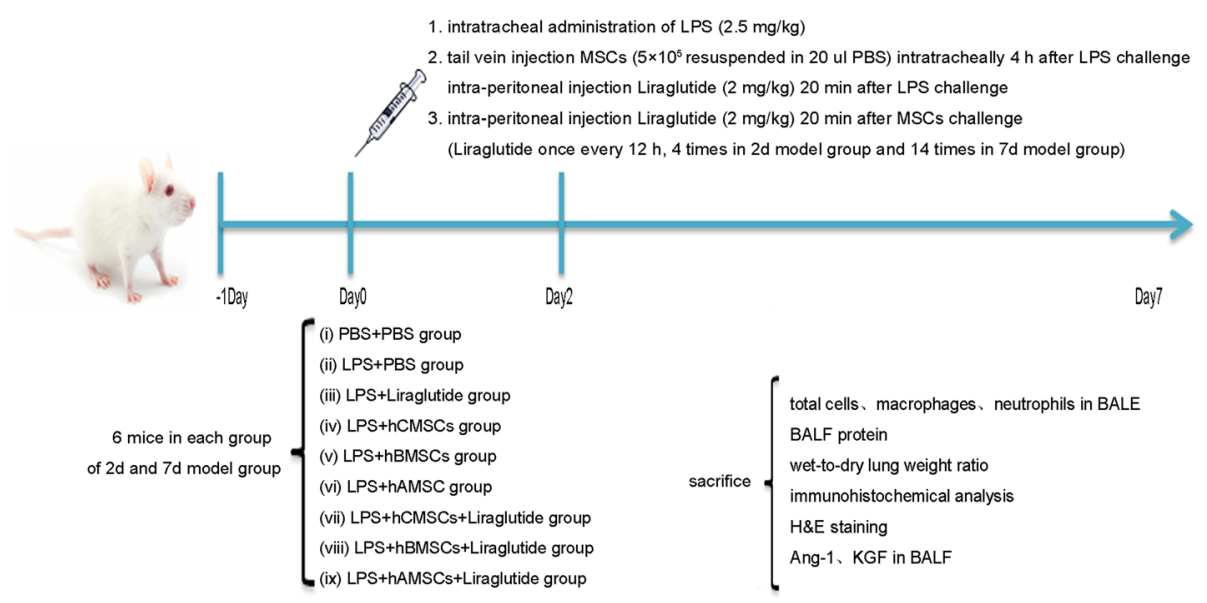

Fig. 1 Animal experiment flow chart. Human chorionic villus-derived mesenchymal stem cells (hCMSCs), human bone marrow-derived mesenchymal stem cells (hBMSCs), human adipose-derived mesenchymal stem cells (hAMSCs), and bronchoalveolar lavage fluid (BALF)

\section{Statistical analysis}

All experiments were repeated at least three times. Quantitative results were expressed as the means \pm standard deviation (SD). The comparison between SiRNA-control and SiRNA-GLP-1R was examined using the Student's $t$ test with SPSS 22.0 software (IBM Corp., Armonk, NY, USA). Comparisons among multiple groups were performed using one-way analysis of variance (ANOVA) with Dunnett's post hoc test and Mann-Whitney test using GraphPad Prism 5.02 software. $P<0.05$ was considered to indicate a statistically significant difference.

\section{Results}

\section{Expression of GLP-1R in three MSCs at different time} points stimulated by LPS

Figure 2 showed the expression of GLP-1R in three MSCs under LPS stimulation. The protein expression of GLP-1R in three MSCs was analyzed by western blot and it decreased gradually with the increase of LPS stimulation time (Fig. 2a). Correspondingly, the ratio of GLP-1R/ GAPDH was significantly reduced (Fig. 2b). The level of GLP-1R in hCMSCs was higher than that of hBMSCs and hAMSCs. GLP-1R at mRNA level was detected by RTqPCR (Fig. 2c). The results showed that the level of GLP$1 \mathrm{R}$ was decreased under the stimulation of LPS, and it was higher in hCMSCs. The fluorescence area and mean intensity were showed the same results (Fig. 2d-g).

\section{Expression of Ang-1, SPC, KGF, and cytokines and} proliferation of three MSCs under the stimulation of LPS and liraglutide

Under the stimulation of LPS, the levels of cytokines IL10 and TNF- $\alpha$-stimulated gene/protein 6 (TSG-6) were reduced, and the degree of inflammation is enhanced. Under the action of liraglutide, the levels of IL-10 and TSG-6 were increased, which reduces the level of inflammation (Additional file 1). To verify whether liraglutide could raise the expression of Ang-1, SPC, and KGF at protein or mRNA level, western blot and RT-qPCR were used to detect the expression at $72 \mathrm{~h}$ (Fig. 3a-d). The expression of KGF was higher in hCMSCs, the expression of Ang-1 was higher in hBMSCs, and the expression of SPC was more in hAMSCs. In order to compare the proliferation of three MSCs under the action of LPS and liraglutide, we observed the growth state of three MSCs by MTT assay. Under the stimulation of LPS, the proliferation of three MSCs decreased at 6, 24, 48, and $72 \mathrm{~h}$. Conversely, liraglutide could significantly enhance MSC growth under LPS stimulation (Fig. 3e-g).

\section{Comparison of apoptosis of three MSCs under the stimulation of LPS alone and combination of liraglutide} In order to compare the apoptosis of three MSCs, western blot was used to detect the expression of apoptotic proteins (Fig. 4a). The expression of cleaved caspase-3 and cleaved caspase- 9 was increased after LPS stimulation for $72 \mathrm{~h}$, and it reversed by addition of liraglutide. The apoptosis of three MSCs was observed by flow cytometry (Fig. 4b-d). Apoptosis ratio increased significantly after MSCs was cultured in LPS-containing medium for $72 \mathrm{~h}$. hCMSCs were most apoptotic MSCs under the stimulation of LPS. Liraglutide could reduce the percentage of apoptosis. The TUNEL experiment further examined the apoptosis of the three MSCs (Fig. $4 \mathrm{e}-\mathrm{g}$ ). The results were consistent with flow cytometry results. hCMSCs had bright green fluorescence intensity under LPS stimulation.

\section{Liraglutide inhibits hCMSCs apoptosis through PKA/ $\beta$ - catenin pathway}

To certify the mechanism of liraglutide exerting antiapoptotic function, we selected hCMSCs with obvious 


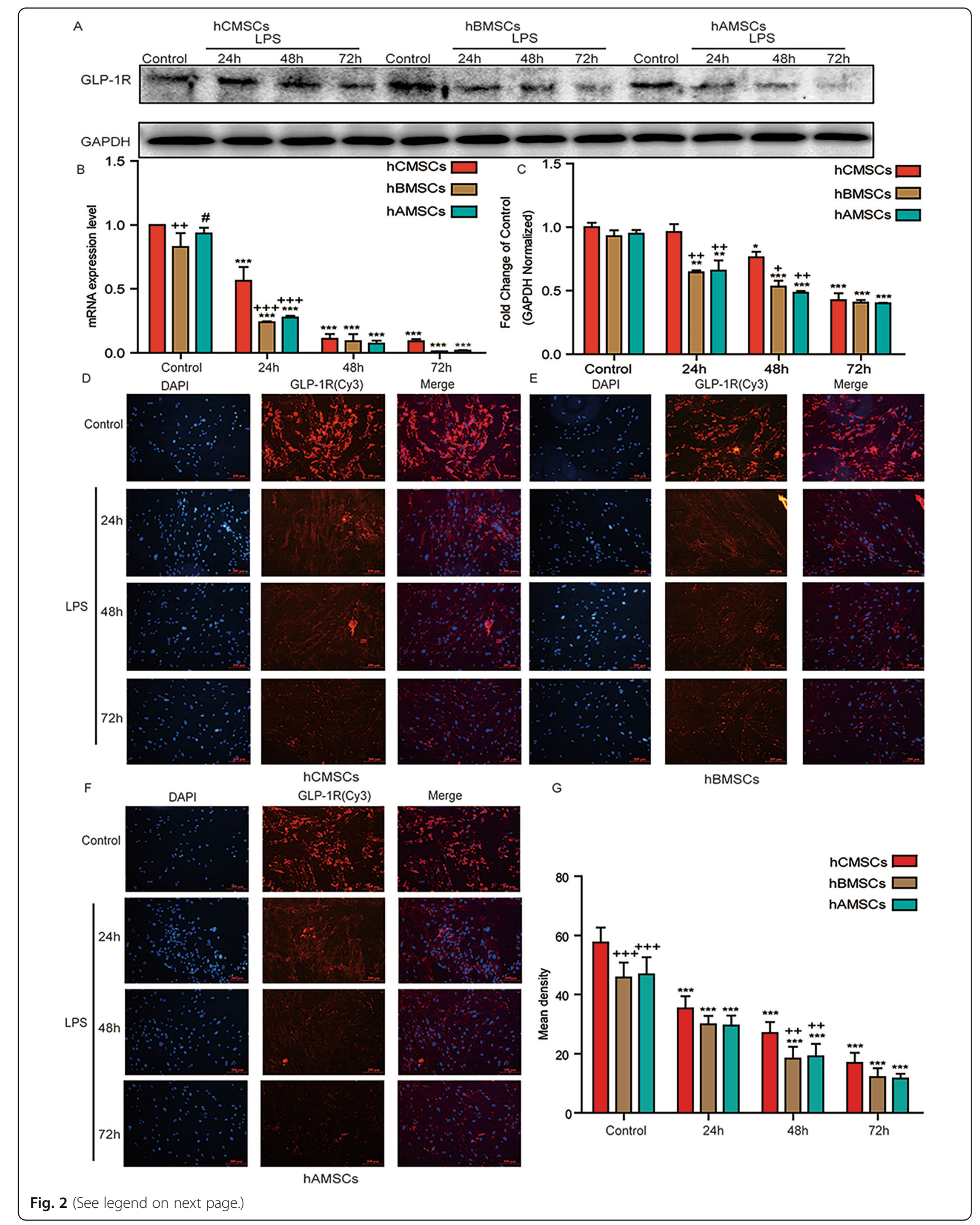


(See figure on previous page.)

Fig. 2 Expression of GLP-1R in three MSCs at different time points under the stimulation of LPS. a-c The expression of GLP-1R in $h C M S C S$, hBMSCs, and hAMSCs in the control group and in $30 \mu \mathrm{g} / \mathrm{mL}$ LPS stimulation for $24 \mathrm{~h}, 48 \mathrm{~h}$, and $72 \mathrm{~h}$ at protein or mRNA level. Fluorescence intensity of GLP-1R in hCMSCs (d), hBMSCs (e), hAMSCs (f), and mean intensity $(\mathbf{g})$ in the control group and $30 \mu \mathrm{g} / \mathrm{mL}$ LPS stimulation for $24 \mathrm{~h}$, $48 \mathrm{~h}$, and $72 \mathrm{~h}$. Blue stands for DAPI and red stands for GLP-1R protein. The representative pictures were showed at $\times 10$ original magnification. Scale bars, $200 \mu \mathrm{m}$, and error bar represent mean \pm SD from three independent experiments. Compared with the control group corresponding to MSCs, ${ }^{*} P<0.05$, ${ }^{* *} P<0.01$, and ${ }^{* * *} P<0.001$; compared with the hCMSCs group corresponding to time points, ${ }^{+} P<0.05,{ }^{++} P<0.01$, and ${ }^{+++} P<$ 0.001; compared with the hBMSCs group corresponding to time points, ${ }^{\#} P<0.05$

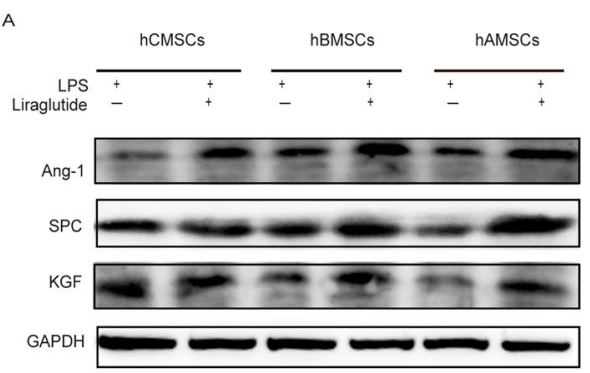

SPC

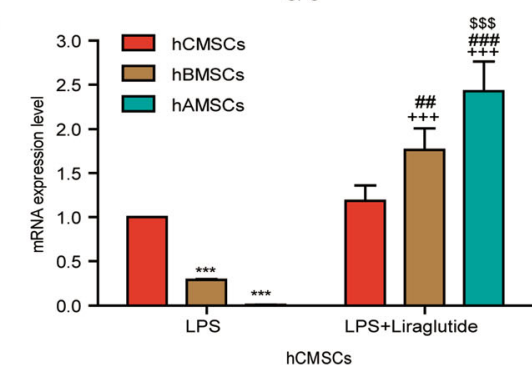

$\mathrm{E}$
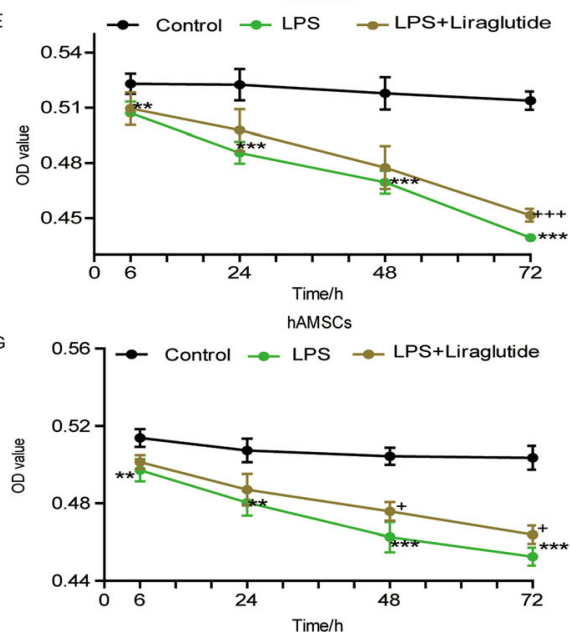

B

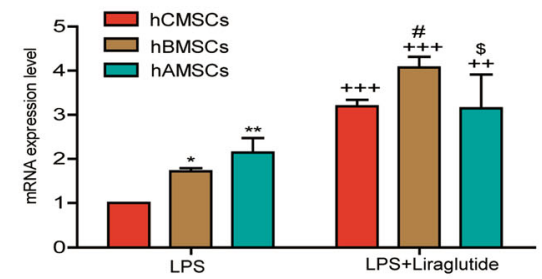

KGF

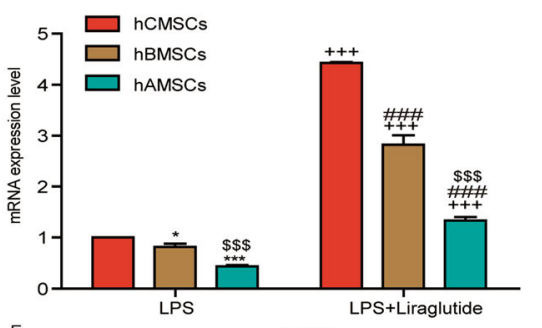

hBMSCS

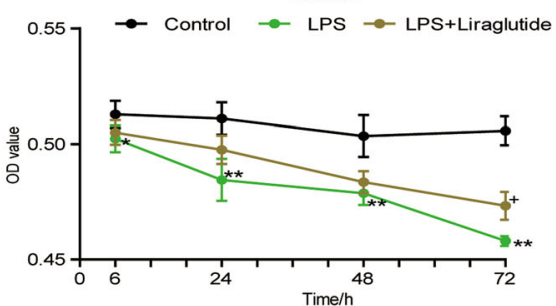

Fig. 3 The expression of Ang-1, SPC, and KGF under the stimulation of LPS alone and combination of liraglutide for $72 \mathrm{~h}$ in three MSCs. a Ang-1, SPC, KGF, $\mathbf{b}$ Ang-1, $\mathbf{c ~ S P C}$, and $\mathbf{d}$ KGF are expressed at protein or mRNA level under the stimulation of $30 \mathrm{\mu g} / \mathrm{mL}$ LPS alone and combination of $10 \mathrm{nM}$ liraglutide at $72 \mathrm{~h}$. Error bars represent mean \pm SD from three independent experiments. Compared with the hCMSCs group stimulated by LPS, ${ }^{*} P<0.05$, ${ }^{* *} P<0.01$, and ${ }^{* * *} P<0.001$; compared with the LPS group corresponding to MSCs, ${ }^{++} P<0.01$ and ${ }^{+++} P<0.001$; compared with the hCMSCs group stimulated by LPS and liraglutide, ${ }^{\#} P<0.05$, ${ }^{\# \#} P<0.01$, and ${ }^{\# \#} P<0.001$; compared with the hBMSCs group stimulated by LPS and with or without liraglutide, ${ }^{\$} P<0.05$ and ${ }^{\$ \$} P<0.001$. The survival rate of hCMSCs $(\mathbf{e})$, hBMSCs (f), and hAMSCs (g) in the control group, LPS group, and LPS + liraglutide group. Error bars represent mean \pm SD from three independent experiments. Compared with the control group corresponding to time points, ${ }^{*} P<0.05$, ${ }^{* *} P<0.01$, and ${ }^{* *} P<0.001$; compared with the LPS group corresponding to time points, ${ }^{+} P<0.05,{ }^{+++} P<0.001$ 


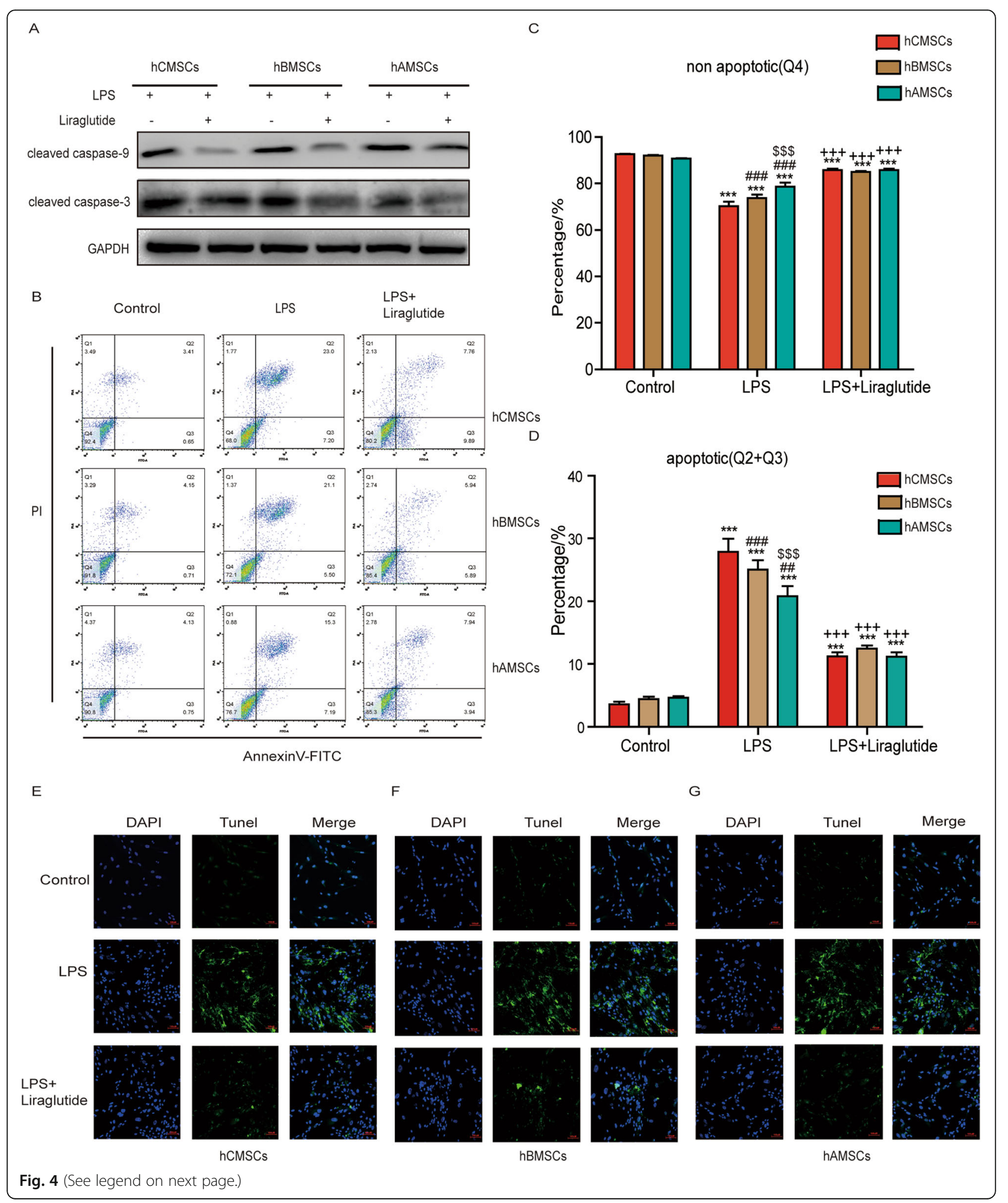




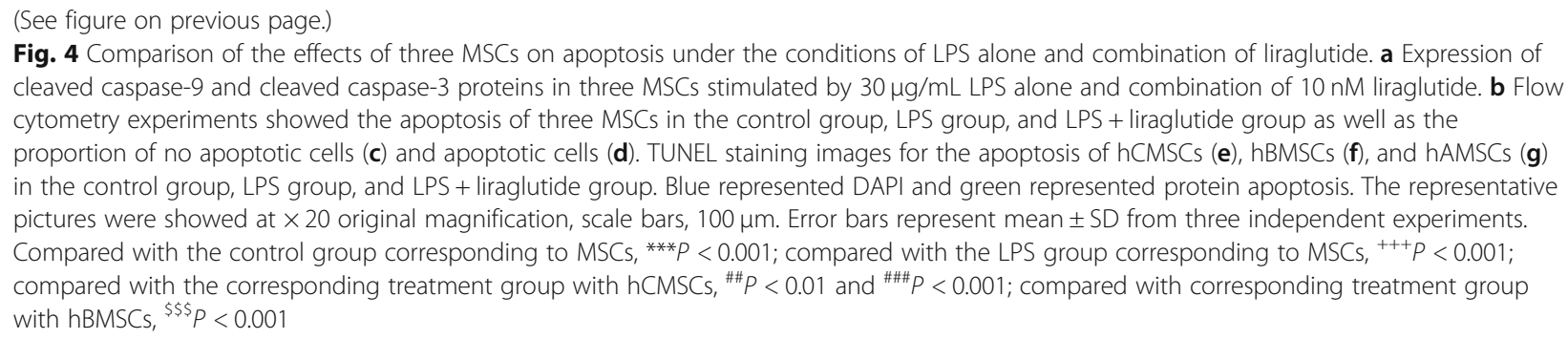

apoptosis as our target cells by flow cytometry and TUNEL assay (Fig. 4b, e-g). Since the classical Wnt/ $\beta$ catenin signaling pathway plays an important role in MSCs, we investigated whether it could participate in the effect of liraglutide on apoptosis of hCMSCs. Liraglutide acted on GLP-1R and we validated the effects of liraglutide by synthesizing exogenous small interfering RNA (SiRNA). Western blot and RT-qPCR were used to analysis of the efficiency of three SiRNA transfections into hCMSCs (Fig. 5a, b), and the Si-3 with the most obvious effect was chosen.

Western blot showed that the expression of phosphorylated $\beta$-catenin ( $\mathrm{p}-\beta$-catenin) by adding Si-GLP-1R was attenuated, the expression of Bax, cleaved caspase-9, and cleaved caspase- 3 were heightened, and the expression of Bcl-2 was decreased, indicating an increase in apoptosis (Fig. 5d, f).

After the addition of liraglutide, hCMSC apoptosis could be reversed. Simultaneously, we used PKA inhibitor H89 to verify MSC apoptosis. The results showed that H89 inhibited the expression of $\mathrm{p}-\beta$-catenin and increased the expression of Bax, cleaved caspase-9, and cleaved caspase-3, further reducing the expression of Bcl-2 (Fig. 5c, e). An addition of liraglutide could reduce the apoptosis of hCMSCs.

\section{The effects of three MSCs alone and combination of liraglutide on acute lung injury in vivo}

$H \& E$ staining of lung sections was performed for histological evaluation of the ALI models. We observed in $2 \mathrm{~d}$ model group that in the PBS + PBS group, the pulmonary tissues were arranged neatly and the alveolar cells were uniform in size. Conversely, in the LPS + PBS group, it was evident that the alveolar septum is increased, the alveolar cavities were severely hemorrhagic, and inflammatory cells infiltrated. In the three MSCs alone groups, the degree of lung injury could be alleviated. However, in the liraglutide alone group, the recovery of lung injury was less effective than the MSCs alone. Simultaneously, in the MSCs combined with liraglutide groups, the extent of lung injury was more pronouncedly relieved and the lung injury scores were reduced (Fig. 6a, b). Same trends were also shown in the $7 \mathrm{~d}$ model group (Additional file 2). And we could conclude that the treatment recovery effect of the $7 d$ model group was preceded than the $2 \mathrm{~d}$ model group, and hCMSCs combined with liraglutide has a certain advantage in relieving ALI symptoms than the combination liraglutide of hBMSCs or hAMSCs.

Total protein concentration in BALF and lung wet-todry ratio are two major indicators for assessing pulmonary edema. In the $2 \mathrm{~d}$ model group, the total protein concentration and wet-to-dry ratio of the LPS + PBS group were significantly higher than those of the PBS + PBS group. Contrary, the total protein concentration and wet-to-dry ratio were decreased in the three MSCs alone groups and liraglutide alone group. In the three MSCs combined with liraglutide groups, the reduction effect was more obvious. Among them, hCMSCs combined with liraglutide reduced the total protein concentration and wet-to-dry ratio more than hBMSCs and hAMSCs (Fig. 6c, d). The number of total cells, neutrophils, and macrophages in BALF was evidently increased in the LPS + PBS group compared with the PBS + PBS group. Among the three MSCs alone groups and liraglutide alone group, the number of cells lessened. There is significant inflammatory cell reduction in the combination MSCs of liraglutide groups (Fig. $6 \mathrm{e}-\mathrm{g}$ ). The $7 \mathrm{~d}$ model group also showed the same results (Additional file 3 ). At the same time, in the $7 \mathrm{~d}$ model group, the recovery of lung injury was brightly greater than that in the $2 \mathrm{~d}$ model group. There is significant improvement in acute lung injury symptoms in mice.

\section{Influence of MSCs alone and combination of liraglutide on the expression of SPC, Ang-1, and KGF in vivo}

SPC is a protein marker of alveolar type II cells (AEC2s). Immunohistochemistry was used to detect the expression of SPC. In the $7 \mathrm{~d}$ model group, it was observed that the expression of lung sections is increased in the three MSCs alone groups and liraglutide alone group, and the expression was more notable in three MSCs combined with liraglutide groups (Fig. 7a). In addition, by examining the expression of Nanog protein [35] in the $2 \mathrm{~d}$ model group, it was found that the expression of Nanog protein increased under the action of liraglutide (Additional file 4). ELISA assay was used to detect the levels of Ang-1 and KGF in BALF. It was found that in the $2 \mathrm{~d}$ 


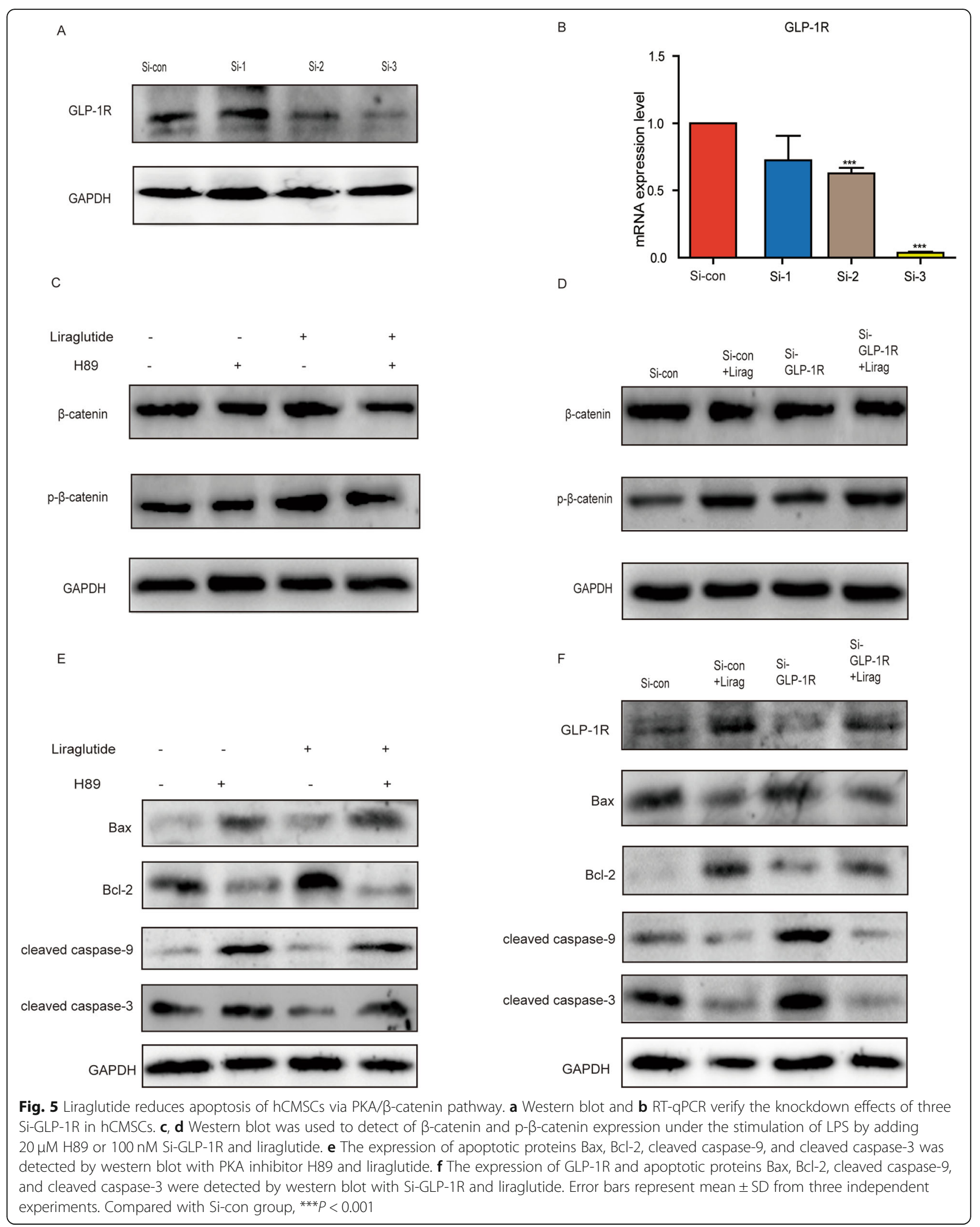




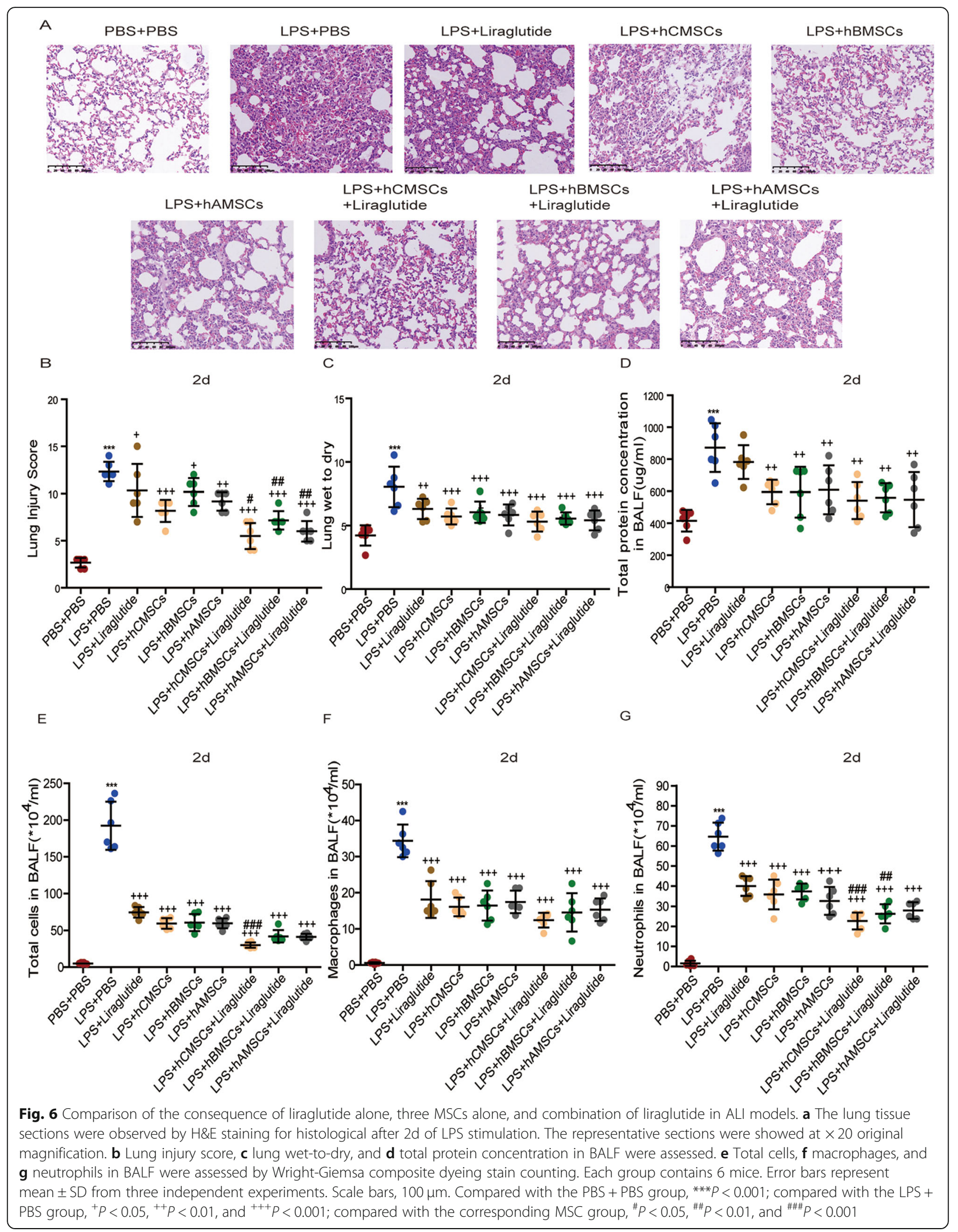




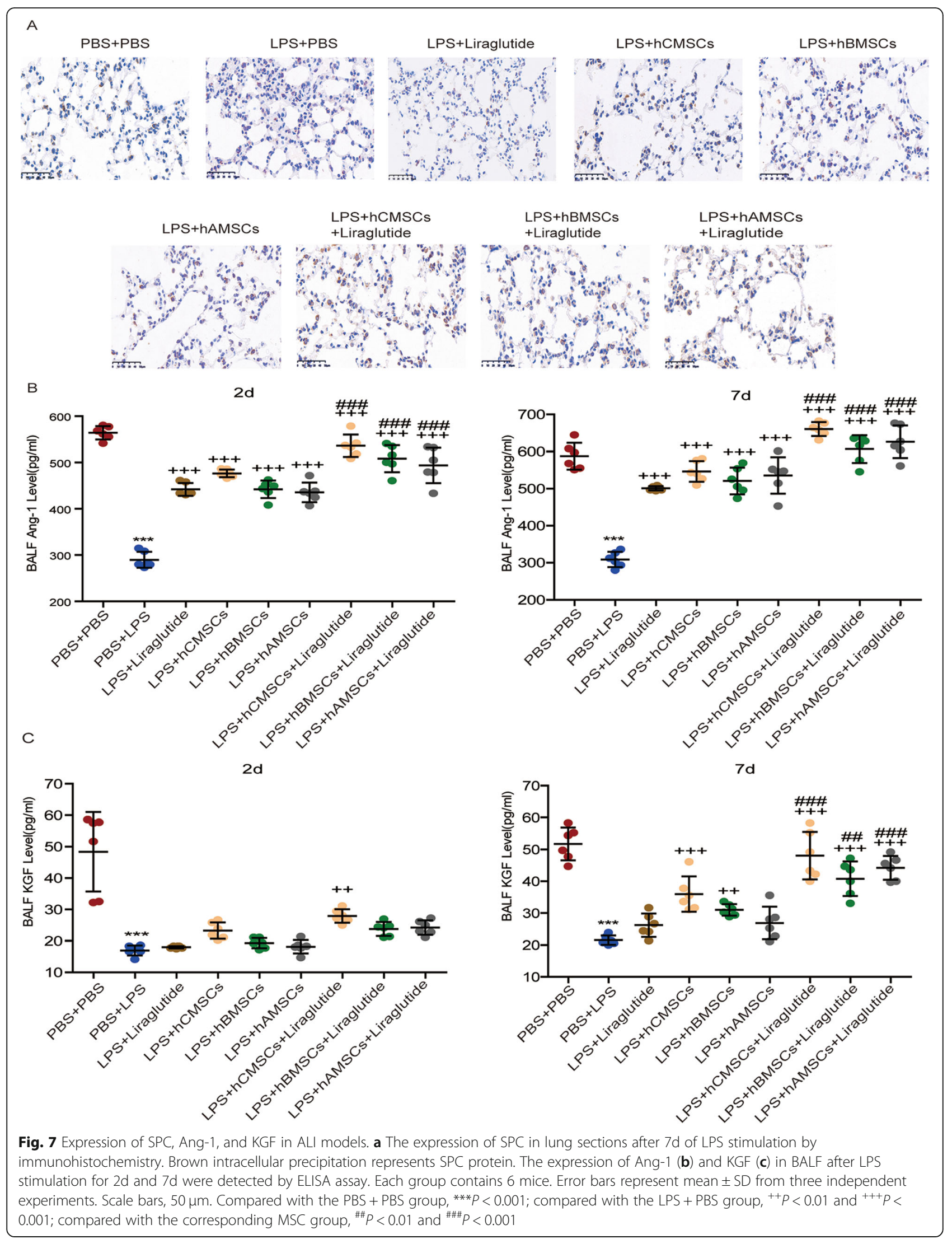


and $7 \mathrm{~d}$ model groups, the levels of Ang-1 and KGF in the LPS + PBS groups were significantly lower than those in the PBS + PBS groups. Although, the concentration was increased in the three MSCs alone groups and liraglutide alone group, the liraglutide alone group was not as effective as the three MSCs alone groups. The increase was more pronounced in the combination of three MSCs of liraglutide groups; moreover, hCMSCs combined with liraglutide has certain advantages over liraglutide combined with hBMSCs or hAMSCs (Fig. 7b, c).

\section{Discussion}

It was reported in preclinical studies that MSCs from different sources have distinct immunomodulatory and biological functions $[13,14,16,18]$. hCMSCs belong to the placenta-derived MSCs and are considered to be alternative source of mesenchymal stem cells [36]. Since hCMSCs are readily obtained, they have superior immunomodulatory functions compared with hBMSCs and hAMSCs [37]. Although hBMSCs are widely used adult stem cells, the cell number and multidirectional differentiation potential of these cells were still affected with aging, which limits their availability in the clinical setting [38].. hAMSCs are an emerging candidate for stem cell therapy because of their similar capabilities and differentiation potential to hBMSCs [39]. Some studies have comparatively analyzed the differential properties and biological function of MSCs derived from human chorionic villus, human bone marrow, and human adipose. Although MSCs from different source share similar antigens, their repair potential for ALI is different. Fewer studies have so far investigated their therapeutic effect difference on ALI. In MSC phase I clinical trial, intravenous MSCs was well tolerated in 9 patients with ARDS, and no serious adverse events were reported with MSC administration after 6 months [40]. Subsequently, a double-blind, randomized trial was conducted in a phase II clinical trial, and 60 eligible patients were selected. No side effects associated with MSCs were found in the trial. However, in the experiment, it was found that the survival rate of MSCs is low, only fluctuating between 36 and $85 \%$ [41]. Due to the short survival rate of MSCs in the ALI model, we found that combined treatment of MSCs is more evident than MSC alone [42-44].

Previous researches have shown that in addition to being effective in glycemic control, GLP-1 could also perform distinct functions in other tissues [28]. GLP-1 has been shown to exert anti-apoptotic effects in several cells, such as nerve cells [45] and cardiomyocytes [46]. Liraglutide is a long-acting agonist of GLP-1, and it has been reported that liraglutide could inhibit cell apoptosis, including renal tubular epithelial cells [47] and osteoblasts [26]. In our previous research, we also found

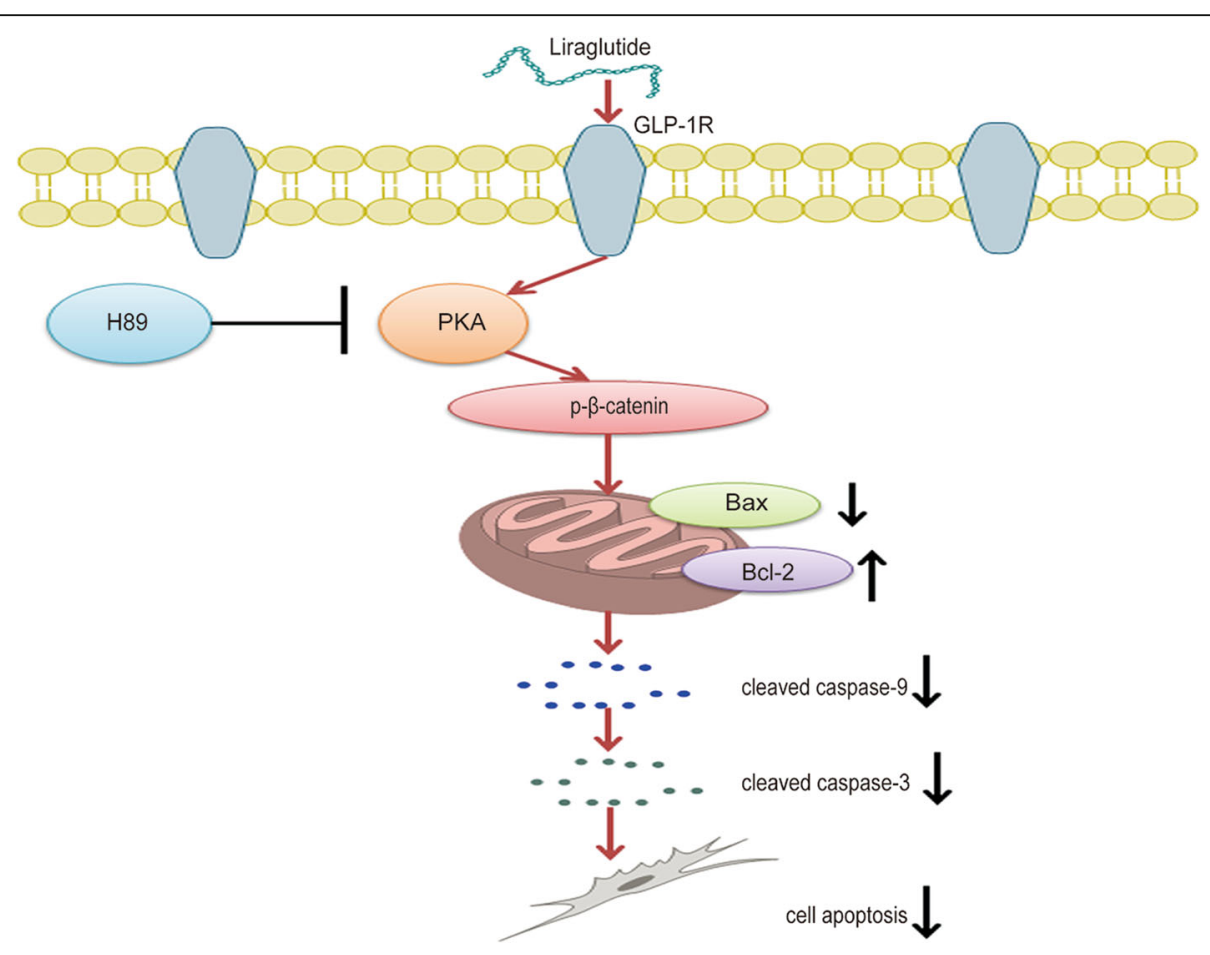

Fig. 8 Schematic showing the regulation of apoptosis in MSCS through the PKA/ $\beta$-catenin pathway. Liraglutide stimulated the expression of PKA by targeting GLP-1R and then motivated the expression of $\beta$-catenin, thereby attenuating the expression of Bax, cleaved caspase- 9 , and cleaved caspase- 3 and enhancing the expression of $\mathrm{BCl}-2$, consequently reducing the apoptosis of MSCs 
that MSCs combined with liraglutide can alleviate the inflammation to some extent and reduce the symptoms of ALI [30]. Taking previous studies into account, we explored whether liraglutide could play a role in treatment of ALI by inhibiting MSCs apoptosis.

In this study, we tested the expression of GLP-1R, SPC, KGF, and Ang-1 in hCMSCs, hBMSCs, and hAMSCs under the action of LPS and liraglutide. We found that the expression of Ang-1, SPC, and KGF are enhanced after adding liraglutide. KGF is considered to be an eventful paracrine soluble factor in MSCs and could stimulate the division of ATII in vivo and in vitro [48]. Ang-1 is a key endothelial survival and vascular stabilizing factor. Recent studies have shown that Ang-1 secreted by MSCs could be responsible for inhibiting pulmonary edema and restoring vascular integrity [49]. SPC is a crucial component of pulmonary surfactant and plays an essential role in the regulation of inflammation. Researches have shown that SPC may affect the microenvironment in bronchoalveolar lavage [50, 51].

Hereafter, we detected whether liraglutide could alleviate the symptoms of ALI by reducing MSC apoptosis. Flow cytometry and TUNEL experiments showed that the apoptosis of three MSCs stimulated by LPS is obvious. The addition of liraglutide reversed the apoptosis of MSCs. Then, we verified whether it could inhibit apoptosis by $\mathrm{PKA} / \beta$-catenin signaling pathway. The expression of apoptotic proteins was examined by the addition of the PKA inhibitor H89 or Si-GLP-1R. Bcl-2 is an antiapoptotic protein that forms a dimer with proapoptotic protein Bax, which could stimulate the expression of apoptotic protein cleaved caspase- 9 and cleaved caspase3 [52, 53]. H89 and Si-GLP-1R could decrease Bcl-2 expression and increase Bax, cleaved caspase-9, and cleaved caspase- 3 expression by inhibiting $p$ - $\beta$-catenin expression. Conversely, the addition of liraglutide reversed these results; the expression of Bax, cleaved caspase-9, and cleaved caspase- 3 were reduced; and Bcl2 was increased. The results indicated that liraglutide could reverse LPS-induced apoptosis by restoring the balance of $\mathrm{Bcl}-2$ protein family and caspase protein family (Fig. 8).

In an in vivo experiment with ALI, we compared the liraglutide alone, three MSCs alone, and combination of liraglutide to observe their repair function. In previous studies, MSCs have been shown to repair ALI $[13-16,19]$, and liraglutide could alleviate the inflammatory environment of ALI [27-29]. In our study, by measuring total protein concentration and cell counts in BALF, wet-to-dry ratio, $\mathrm{H} \& \mathrm{E}$ staining, and lung injury scores, we conclude that liraglutide or MSCs alone and combination of liraglutide could ameliorate the symptoms of ALI. In particular, through the comparison of three MSCs, it was found that hCMSCs combined with liraglutide have a relative advantage in the recovery of symptoms in ALI mice. This trend was also observed in SPC immunohistochemistry experiment as well as the concentration of Ang-1 and KGF. However, the increased expression of SPC in lung tissues may be due to themselves or the secretion of AEC2s stimulated by MSCs. The specific mechanism is unknown, and further investigation is needed.

\section{Conclusions}

Based on our research, we concluded that the effect of MSC combination of liraglutide was prioritized to MSCs or liraglutide alone in the treatment of ALI. Through the PKA/ $\beta$-catenin signaling pathway, liraglutide could reduce the apoptosis of MSCs. Simultaneously, the degree of lung injury could be ameliorated by increasing the expression of Ang-1, SPC, and KGF, thereby alleviating the symptoms of ALI.

\section{Supplementary information}

Supplementary information accompanies this paper at https://doi.org/10 1186/s13287-020-01689-5.

Additional file 1: Figure S1.The levels of IL-10(A) and TSG-6(B) in culture supernatant. Three kinds of MSCs were stimulated with LPS and Liraglutide for $72 \mathrm{~h}$, then the culture supernatants were collected, and the expression levels of IL-10 and TSG- 6 were detected by Elisa assay. Error bars represent mean \pm SD from three independent experiments. (Compared with the Control group of corresponding MSCs group, ${ }^{* * *} P<$ 0.001; compared with LPS group of corresponding MSCs group, ${ }^{+++} P<$ 0.001 ; compared with LPS+Liraglutide groups of hCMSCs group, ${ }^{\#} P<0.05$, $\#$ \# $P<0.01$.).

Additional file 2. Comparison of the lung injury therapy of liraglutide alone, three MSCS alone and combination of liraglutide in the 7d ALI models. (A) The lung tissue sections were observed by H\&E staining for histological after 7d of LPS stimulation. The representative sections were showed at 20x original magnification. (B) Lung injury score was measured. Scale bars, $100 \mu \mathrm{m}$. Each group contains 6 mice. Error bars represent mean \pm SD from three independent experiments. (Compared with PBS+PBS group, ${ }^{* * *} P<0.001$; compared with LPS+PBS group, ${ }^{+} P<0.05$, ${ }^{++} P<0.01,{ }^{++} P<0.001$; compared with the corresponding MSCs group, ${ }^{\#} P<$ $\left.0.05,{ }^{\#} P<0.01\right)$

Additional file 3. Comparison of the lung fluid clears and inflammatory cells of liraglutide alone, three MSCs alone and combination of liraglutide in the 7d ALI models. (A) lung wet-to-dry, (B) total protein concentration in BALF were assessed. (C) Total cells, (D) macrophages, (E) neutrophils in BALF were assessed by Wright-Giemsa composite dyeing stain counting. Each group contains 6 mice. Error bars represent mean \pm SD from three independent experiments. (Compared with PBS+PBS group, ${ }^{* * *} P<0.001$; compared with LPS+PBS group, ${ }^{+} P<0.05,{ }^{++} P<0.01,{ }^{++} P<0.001$; compared with the corresponding MSCs group ${ }^{\#} P<0.05,{ }^{\# \#} P<0.001$ ).

Additional file 4. Immunohistochemistry detected Nanog protein expression in mice lung tissues. The expression of Nanog in lung tissue was detected on the $2 \mathrm{~d}$ after LPS stimulation. Each group contains 6 mice. Scale bars, $50 \mu \mathrm{m}$.

\section{Abbreviations}

MSCs: Mesenchymal stem cells; hCMSCs: Human chorionic villus-derived mesenchymal stem cells; hBMSCs: Human bone marrow-derived mesenchymal stem cells; hAMSCs: Human adipose-derived mesenchymal stem cells; ALI: Acute lung injury; ARDS: Acute respiratory distress syndrome; GLP1: Glucagon-like peptide-1; GLP-1R: GLP-1 receptor; Ang-1: Angiopoietin 1; SPC: SFTPC; BALF: Bronchoalveolar lavage fluid; W/D: Wet-to-dry ratio; SiRNA: Small interfering RNA.; AEC2s: Alveolar type II cells 


\section{Acknowledgements}

The authors would like to thank the East China University of Science and Technology for providing the experiment platform. We would also like to thank Prof. Jianming Zhang in the high-throughput screening core, National Research Center for Translational Medicine (Shanghai) for his help of manuscript revising.

\section{Authors' contributions}

$J \mathrm{~L}, J \mathrm{Q}$, and $\mathrm{YF}$ designed the experiments and revised the manuscript. $X Y, Y F$, and $X M$ performed the experiments. $X Y$ wrote the manuscript. $Y F, X Y$, and $X C$ analyzed the data. OD and YS revised the manuscript. The authors read and approved the final manuscript.

\section{Funding}

This study was supported by the National Natural Science Foundation of China (81630001, 81570066), Shanghai Municipal Key Clinical Specialty (shslczdzk02202), Shanghai Top-Priority Clinical Key Disciplines Construction Project(2017ZZ02014), Shanghai Jiao Tong University Medical Cross Project (YG2017MS64), Shanghai Natural Science Foundation (18ZR1424000), Shanghai Shenkang Hospital Development Center Clinical Science and Technology Innovation Project (SHDC12018102), and National Innovative Research Team of High-level Local Universities in Shanghai.

\section{Availability of data and materials}

The data that support the findings of this study are available from the corresponding author upon reasonable request.

\section{Ethics approval and consent to participate}

All animal experiments were approved by the guidelines for the care and use of laboratory animals authorized by Ministry of Science and Technology of the People's Republic of China and approved by Zhongshan Hospital Affiliated to Fudan University. All animal experiments were conducted in the School of Pharmacy, East China University of Science and Technology. All efforts were made to minimize the number and suffering of the included animals.

\section{Consent for publication}

Not applicable.

\section{Competing interests}

The authors declare that they have no competing interests.

\section{Author details}

'Department of Respiratory and Critical Care Medicine, Ruijin Hospital, School of Medicine, Shanghai Jiao Tong University, Shanghai 20025, China. ${ }^{2}$ State Key Laboratory of Bioreactor Engineering \& Shanghai Key Laboratory of New Drug Design, School of Pharmacy, East China University of Science and Technology, Shanghai 200237, China. ${ }^{3}$ Department of Pulmonary Medicine, Zhongshan Hospital, Fudan University, Shanghai 20003, China. ${ }^{4}$ Department of Pathology, Ruijin Hospital, School of Medicine, Shanghai Jiao Tong University, Shanghai 20025, China. ${ }^{5}$ Institute of Respiratory Diseases, School of Medicine, Shanghai Jiao Tong University, Shanghai 20025, China.

\section{Received: 28 January 2020 Revised: 19 March 2020} Accepted: 23 April 2020 Published online: 19 May 2020

\section{References}

1. Nargesi L, Eirin A. Mesenchymal stem cell-derived extracellular vesicles for renal repair. Curr Gene Ther. 2017;17:29-42. https://doi.org/10.2174/ 1566523217666170412110724.

2. Spadaro $\mathrm{P}$, Turrini $\mathrm{T}$, Thwaites $\mathrm{M}$, et al. Biomarkers for acute respiratory distress syndrome and prospects for personalised medicine. J Inflamm (Lond). 2019;16:1. https://doi.org/10.1186/s12950-018-0202-y.

3. Matthay Z, Zimmerman A, Beitler M, et al. Acute respiratory distress syndrome. Nat Rev Dis Primers. 2019;5:18. https://doi.org/10.1038/s41572019-0069-0.

4. Patel VJ, Roy SB, Mehta HJ, Joo M, Sadikot RT. Alternative and natural therapies for acute lung injury and acute respiratory distress syndrome. Biomed Res Int. 2018;2018:2476824. https://doi.org/10.1155/2018/2476824.
5. Villar J, Slutsky AS. GOLDEN anniversary of the acute respiratory distress syndrome: still much work to do! Curr Opin Crit Care. 2017;23:4-9. https:// doi.org/10.1097/MCC.0000000000000378.

6. Ferguson. Clinical review: acute respiratory distress syndrome - clinical ventilator management and adjunct therapy. Critical Care. 2013;17:225. https://doi.org/10.1186/cc11867.

7. Guo L, Wang W, Zhao N, Guo L, Chi C, Hou W, et al. Mechanical ventilation strategies for intensive care unit patients without acute lung injury or acute respiratory distress syndrome: a systematic review and network meta-analysis. Critical Care. 2016;20:226. https://doi.org/10.1186/ s13054-016-1396-0.

8. Munshi L, Del Sorbo L, Adhikari NKJ, Hodgson CL, Wunsch H, Meade MO, et al. Prone position for acute respiratory distress syndrome. A systematic review and meta-analysis. Ann Am Thorac Soc. 2017;14:S280-S8. https://doi. org/10.1513/AnnalsATS.201704-3430T.

9. Penot-Ragon. Neuromuscular blockers in early acute respiratory distress syndrome. N Engl J Med. 2010;363:1107-16. https://doi.org/10.1056/ NEJMoa1005372.

10. Wiedemann HP, Wheeler AP, Bernard GR. Comparison of two fluidmanagement strategies in acute lung injury. J Vasc Surg. 2006;44:2564-75. https://doi.org/10.1016/j.jvs.2006.08.053.

11. Nerlich M. Endotoxin exacerbates lung injury Burns. 1983;10:148. doi:org /https://doi.org/10.1016/0305-4179(83)90026-8.

12. Pinkerton JW, Kim RY, Robertson AAB, Hirota JA, Wood LG, Knight DA, et al. Inflammasomes in the lung. Mol Immunol. 2017;86:44-55. https://doi.org/10. 1016/j.molimm.2017.01.014

13. Hao Q, Zhu Y-G, Monsel A, Gennai S, Lee T, Fengyun X, et al. Study of bone marrow and embryonic stem cell-derived human mesenchymal stem cells for treatment of Escherichia coli endotoxin-induced acute lung injury in mice. Stem Cells Transl Med. 2015;4:832-40. https://doi.org/10.5966/sctm. 2015-0006.

14. Ho MSH, Mei SHJ, Stewart DJ. The immunomodulatory and therapeutic effects of mesenchymal stromal cells for acute lung injury and sepsis. J Cell Physiol. 2015;230:2606-17. https://doi.org/10.1002/jcp.25028.

15. Sinclair K, Yerkovich ST, Chambers DC. Mesenchymal stem cells and the lung. Respirology. 2013;18:397-411. https://doi.org/10.1111/resp.12050.

16. Shalaby SM, El-Shal AS, Abd-Allah SH, Selim AO, Selim SA, Gouda ZA, et al. Mesenchymal stromal cell injection protects against oxidative stress in Escherichia coli-induced acute lung injury in mice. Cytotherapy. 2014;16:76475. https://doi.org/10.1016/j.jcyt.2013.12.006.

17. Shi Y, Hu G, Su J, Li W, Chen Q, Shou P, et al. Mesenchymal stem cells: a new strategy for immunosuppression and tissue repair. Cell Res. 2010;20: 510-8. https://doi.org/10.1038/cr.2010.44.

18. Shi Y, Wang Y, Li Q, Liu K, Hou J, Shao C, et al. Immunoregulatory mechanisms of mesenchymal stem and stromal cells in inflammatory diseases. Nat Rev Nephrol. 2018;14:493-507. https://doi.org/10.1038/s41581018-0023-5.

19. Feng $Y, X u$ Q, Yang $Y$, Shi W, Meng W, Zhang $H$, et al. The therapeutic effects of bone marrow-derived mesenchymal stromal cells in the acute lung injury induced by sulfur mustard. Stem Cell Res Ther. 2019;10:90. https://doi.org/10.1186/s13287-019-1189-x.

20. Lu H, Cook T, Poirier C, Merfeld-Clauss S, Petrache I, March KL, et al. Pulmonary retention of adipose stromal cells following intravenous delivery is markedly altered in the presence of ARDS. Cell Transplant. 2016;25:163543. https://doi.org/10.3727/096368915X690189.

21. Fukuchi Y. Human placenta-derived cells have mesenchymal stem/ progenitor cell potential. Stem Cells. 2004;22:649-58. https://doi.org/10. 1634/stemcells.22-5-649.

22. Baksh D, Yao R, Tuan RS. Comparison of proliferative and multilineage differentiation potential of human mesenchymal stem cells derived from umbilical cord and bone marrow. Stem Cells. 2007;25:1384-92. https://doi. org/10.1634/stemcells.2006-0709.

23. Park J-C, Kim J-M, Jung I-H, Kim JC, Choi S-H, Cho K-S, et al. Isolation and characterization of human periodontal ligament (PDL) stem cells (PDLSCS) from the inflamed PDL tissue: in vitro and in vivo evaluations. J Clin Periodontol. 2011;38:721-31. https://doi.org/10.1111/ j.1600-051X. 2011.01716.X

24. Hoffman AM, Paxson JA, Mazan MR, Davis AM, Tyagi S, Murthy S, et al. Lung-derived mesenchymal stromal cell post-transplantation survival, persistence, paracrine expression, and repair of elastase-injured lung. Stem Cells Dev. 2011;20:1779-92. https://doi.org/10.1089/scd.2011.0105.

25. Zhang S, Jiang W, Ma L, Liu Y, Zhang X, Wang S. Nrf2 transfection enhances the efficacy of human amniotic mesenchymal stem cells to repair lung 
injury induced by lipopolysaccharide. J Cell Biochem. 2018;119:1627-36. https://doi.org/10.1002/jcb.26322.

26. Wu X. Liraglutide inhibits the apoptosis of MC3T3-E1 cells induced by serum deprivation through CAMP/PKA/ $\beta$-catenin and PI3K/AKT/GSK3 $\beta$ signaling pathways. Mol Cells. 2018;41:234-43. https://doi.org/10.14348/ molcells.2018.2340.

27. Zhou F, Zhang Y, Chen J, Hu X, Xu Y. Liraglutide attenuates lipopolysaccharide-induced acute lung injury in mice. Eur J Pharmacol. 2016;791:735-40. https://doi.org/10.1016/j.ejphar.2016.10.016.

28. Bruen R, Curley S, Kajani S, Crean D, O'Reilly ME, Lucitt MB, et al. Liraglutide dictates macrophage phenotype in apolipoprotein E null mice during early atherosclerosis. Cardiovasc Diabetol. 2017;16:143. https://doi.org/10.1186/ s12933-017-0626-3.

29. Qi Q, Lu L, Li H, Yuan Z, Chen G, Lin M, et al. Spatiotemporal delivery of nanoformulated liraglutide for cardiac regeneration after myocardial infarction. Int J Nanomedicine. 2017;12:4835-48. https://doi.org/10.2147/IJN. S132064.

30. Feng $Y$, Wang L, Ma X, Yang X, Don O, Chen $X$, et al. Effect of hCMSCs and liraglutide combination in ALI through CAMP/PKAc/beta-catenin signaling pathway. Stem Cell Res Ther. 2020;11:2. https://doi.org/10.1186/s13287-0191492-6.

31. Ji S, Wu C, Tong L, Wang L, Zhou J, Chen C, et al. Better therapeutic potential of bone marrow-derived mesenchymal stem cells compared with chorionic villi-derived mesenchymal stem cells in airway injury model. Regen Med. 2019;14:165-77. https://doi.org/10.2217/rme-2018-0152.

32. Fang B, Liu Y, Zheng D, Shan S, Wang C, Gao Y, et al. The effects of mechanical stretch on the biological characteristics of human adiposederived stem cells. J Cell Mol Med. 2019;23:4244-55. https://doi.org/10.1111/ jcmm.14314.

33. Zhu T, Li C, Zhang X, Ye C, Tang S, Zhang W, et al. GLP-1 analogue liraglutide enhances SP-A expression in LPS-induced acute lung injury through the TTF-1 signaling pathway. Mediators Inflamm. 2018;2018: 3601454. https://doi.org/10.1155/2018/3601454.

34. Mrozek JD. Exogenous surfactant and partial liquid ventilation: physiologic and pathologic effects. Am J Respir Crit Care Med. 1997;156:1058-65. https://doi.org/10.1164/ajrccm.156.4.9610104.

35. Hostettler KE, Gazdhar A, Khan P, Savic S, Tamo L, Lardinois D, et al. Multipotent mesenchymal stem cells in lung fibrosis. PLoS One. 2017;12: e0181946. https://doi.org/10.1371/journal.pone.0181946.

36. Parolini O, Alviano F, Bagnara GP, Bilic G, Bühring $\mathrm{H}-\mathrm{J}$, Evangelista $\mathrm{M}$, et al. Concise review: isolation and characterization of cells from human term placenta: outcome of the first international Workshop on Placenta Derived Stem Cells. Stem Cells. 2008;26:300-11. https://doi.org/10.1634/stemcells. 2007-0594.

37. Lee JM, Jung J, Lee H-J, Jeong SJ, Cho KJ, Hwang S-G, et al. Comparison of immunomodulatory effects of placenta mesenchymal stem cells with bone marrow and adipose mesenchymal stem cells. Int Immunopharmacol. 2012; 13:219-24. https://doi.org/10.1016/j.intimp.2012.03.024.

38. Chen J-Y, Mou X-Z, Du X-C, Xiang C. Comparative analysis of biological characteristics of adult mesenchymal stem cells with different tissue origins. Asian Pac J Trop Med. 2015;8:739-46. https://doi.org/10.1016/j.apjtm.2015. 07.022.

39. Silva JD, Lopes-Pacheco M, Paz AHR, Cruz FF, Melo EB, de Oliveira MV, et al. Mesenchymal stem cells from bone marrow, adipose tissue, and lung tissue differentially mitigate lung and distal organ damage in experimental acute respiratory distress syndrome. Crit Care Med. 2018;46:e132-e40. https://doi. org/10.1097/CCM.0000000000002833.

40. Wilson JG, Liu KD, Zhuo H, Caballero L, McMillan M, Fang X, et al. Mesenchymal stem (stromal) cells for treatment of ARDS: a phase 1 clinical trial. Lancet Respir Med. 2015;3:24-32. https://doi.org/10.1016/s22132600(14)70291-7

41. Matthay MA, Calfee CS, Zhuo H, Thompson BT, Wilson JG, Levitt JE, et al. Treatment with allogeneic mesenchymal stromal cells for moderate to severe acute respiratory distress syndrome (START study): a randomised phase 2a safety trial. Lancet Respir Med. 2019;7:154-62. https://doi.org/10. 1016/s2213-2600(18)30418-1.

42. Huang Z, Liu H, Zhang X, Wen G, Zhu C, Zhao Y, et al. Transcriptomic analysis of lung tissues after hUC-MSCS and FTY720 treatment of lipopolysaccharide-induced acute lung injury in mouse models. Int Immunopharmacol. 2018;63:26-34. https://doi.org/10.1016/.intimp.2018.06.036.
43. Han J, Lu X, Zou L, Xu X, Qiu H. E-prostanoid 2 receptor overexpression promotes mesenchymal stem cell attenuated lung injury. Hum Gene Ther. 2016;27:621-30. https://doi.org/10.1089/ hum. 2016.003.

44. Sun C. EPO enhances the protective effects of MSCs in experimental hyperoxia-induced neonatal mice by promoting angiogenesis. Aging. 2019; 11:2477-87. https://doi.org/10.1862/ aging.101937.

45. Deng C, Cao J, Han J, Li J, Li Z, Shi N, et al. Liraglutide activates the Nrf2/ HO-1 antioxidant pathway and protects brain nerve cells against cerebral ischemia in diabetic rats. Comput Intell Neurosci. 2018;2018:3094504. https://doi.org/10.1155/2018/3094504

46. Hu S-Y, Zhang Y, Zhu P-J, Zhou H, Chen Y-D. Liraglutide directly protects cardiomyocytes against reperfusion injury possibly via modulation of intracellular calcium homeostasis. J Geriatr Cardiol. 2017;14:57-66. https:// doi.org/10.11909/j.issn.1671-5411.2017.01.008.

47. Zhao X, Liu G, Shen H, Gao B, Li X, Fu J, et al. Liraglutide inhibits autophagy and apoptosis induced by high glucose through GLP-1R in renal tubular epithelial cells. Int J Mol Med. 2015;35:684-92. https://doi.org/10.3892/ijmm. 2014.2052.

48. Chen J, Li C, Gao X, Li C, Liang Z, Yu L, et al. Keratinocyte growth factor gene delivery via mesenchymal stem cells protects against lipopolysaccharide-induced acute lung injury in mice. PLoS One. 2013;8: e83303. https://doi.org/10.1371/journal.pone.0083303.

49. Tang X-D, Shi L, Monsel A, Li X-Y, Zhu H-L, et al. Mesenchymal stem cell microvesicles attenuate acute lung injury in mice partly mediated by Ang-1 mRNA. Stem Cells. 2017;35:1849-59. https://doi.org/10.1002/stem.2619.

50. Jin H, Ciechanowicz AK, Kaplan AR, Wang L, Zhang P-X, Lu Y-C, et al. Surfactant protein $C$ dampens inflammation by decreasing JAK/STAT activation during lung repair. Am J Physiol Lung Cell Mol Physiol. 2018;314: L882-L92. https://doi.org/10.1152/ajplung.00418.2017.

51. Islam D. Identification and modulation of microenvironment is crucial for effective MSC therapy in acute lung injury. Am J Respir Crit Care Med. 2018; 199:1214-24. https://doi.org/10.1164/rccm.201802-03560C.

52. Li B, Zhang $H$, Zeng $M$, He W, Li M, Huang $X$, et al. Bone marrow mesenchymal stem cells protect alveolar macrophages from lipopolysaccharide-induced apoptosis partially by inhibiting the Wnt/betacatenin pathway. Cell Biol Int. 2015;39:192-200. https://doi.org/10.1002/cbin. 10359.

53. Chen S, Cui G, Peng C, Lavin MF, Sun X, Zhang E, et al. Transplantation of adipose-derived mesenchymal stem cells attenuates pulmonary fibrosis of silicosis via anti-inflammatory and anti-apoptosis effects in rats. Stem Cell Res Ther. 2018;9:110. https://doi.org/10.1186/s13287-018-0846-9.

\section{Publisher's Note}

Springer Nature remains neutral with regard to jurisdictional claims in published maps and institutional affiliations.

Ready to submit your research? Choose BMC and benefit from:

- fast, convenient online submission

- thorough peer review by experienced researchers in your field

- rapid publication on acceptance

- support for research data, including large and complex data types

- gold Open Access which fosters wider collaboration and increased citations

- maximum visibility for your research: over $100 \mathrm{M}$ website views per year

At $\mathrm{BMC}$, research is always in progress.

Learn more biomedcentral.com/submission 